\title{
Continuous Culture of Yeast on Phenol
}

\author{
By D. A. J. WASE AND J. S. HOUGH \\ Department of Biochemistry, University of Birmingham
}

(Received 8 June 1965)

\begin{abstract}
SUMMARY
Debaryomyces subglobosus ( $\mathrm{NCYC} 459$ ) was grown in continuous culture at $30^{\circ}$ in media containing $3,6 \cdot 65,9$ and $12 \mu$ moles phenol $/ \mathrm{ml}$. as sole source of carbon. With each medium, wash-out of organisms occurred at dilution rates in the range $0 \cdot 33-0 \cdot 36 \mathrm{hr}^{-1}$. The yeasts became quickly adapted to the medium with lowest phenol content and grew readily at dilution rates between $0 \cdot 1$ and $0 \cdot 3 \mathrm{hr}^{-1}$. At lower dilution rates, however, the endogenous metabolism of the yeasts tended to outstrip the rate at which phenol was supplied. With $9 \mu \mathrm{moles} \mathrm{phenol} / \mathrm{ml}$. the best rate of output of yeast was achieved but at $6.65 \mu \mathrm{moles}$ phenol $/ \mathrm{ml}$., was most fully utilized, utilization being complete up to a dilution rate of $0.3 \mathrm{hr}^{-1}$. At the highest contents of phenol in the medium, the yeast adapted less readily and produced considerable amounts of riboflavin. The population became heterogeneous, with some yeasts clumping and others large and fragile. There was some evidence that the latter were unable to metabolize phenol but could utilize catechol, a product of metabolism of the normal organisms.

The appendix provides a comparison between the reported results and those calculated from the growth constants using classical mathematical treatment of continuous culture. Substantial deviations are attributed to high maintenance energy requirements, flocculation of the yeast and toxicity of the medium.
\end{abstract}

\section{INTRODUCTION}

The breakdown of phenols by micro-organisms has received considerable attention because of its biochemical interest and its industrial importance in effluent treatment. In metabolic studies, attention has been principally focused on pseudomonads and vibrioform bacteria (Evans, 1963), while studies on industrial effluents have usually involved undefined mixtures of micro-organisms (Evans \& Kite, 1961). Recently, the ability of yeasts to degrade phenol has been investigated (Harris \& Ricketts, 1962) and, at least on pilot plant scale has been exploited commercially (Reiche, Hilgetag, Lorenz \& Martini, 1962). The metabolic pathways involved have been shown to be similar to methods of breakdown of phenols by bacteria (Wase \& Hough, to be published).

Special problems attend the use of toxic materials as substrates for microorganisms and this is particularly apparent when phenols are used as the sole source of carbon. It has been shown in batch culture by Wase \& Hough (1965) that selected yeasts will grow on low concentrations of phenol after a period of adaptation. With such limited supplies of carbon, however, the period of growth is very short in comparison with the lag period. After the phenol has been exhausted, the 
yeast de-adapts quickly and a further lengthy period of adaptation is necessary before a fresh supply of phenol can be attacked. Continuous culture was therefore used to supply organisms fully adapted to phenol.

\section{METHODS}

Organism. Debaryomyces subglobosus (Zach) Lodder \& Kreger-van Rij, strain NCYC 459, was obtained from the National Collection of Yeast Cultures, Brewing Industry Research Foundation, Nutfield, Redhill, Surrey. Stock cultures were maintained by monthly subculture on medium $(a)$.

Media. (a) $10 \%$ (w/v) malt-wort was steamed with $2 \%(\mathrm{w} / \mathrm{v})$ agar for $1 \mathrm{hr}$. The medium was dispensed in screw-cap bottles which were sloped after final sterilization.

(b) The medium used for continuous culture is given in Table 1. It was only effective for periods under 10 days because the pyridoxine was unstable. Phenol was always the limiting nutrient.

Table 1. Composition of the growth medium

(i) Basal solution

The following were dissolved in order in distilled water and made up to $7990 \mathrm{ml}$.:

$\left(\mathrm{NH}_{4}\right)_{2} \mathrm{HPO}_{4}, 19 \cdot 0 \mathrm{~g}$. $\mathrm{KH}_{2} \mathrm{PO}_{4}, 16.0 \mathrm{~g} . ; \mathrm{MgSO}_{4} .7 \mathrm{H}_{2} \mathrm{O}, 8.0 \mathrm{~g}$.; $\mathrm{HCl}$ (conc.), $4 \mathrm{ml}$.; $\mathrm{CaCl}_{2} .6 \mathrm{H}_{2} \mathrm{O}$, $\mathbf{2 \cdot 0} \mathrm{g}$.

(ii) Trace element solutions

Solution A: KI (0.1\%, w/v, aqueous solution), $0.8 \mathrm{ml}$. added to basal solution.

Solution B: the following were dissolved in order in distilled water and made up to $100 \mathrm{ml}$. : $\mathrm{FeSO}_{4} .7 \mathrm{H}_{2} \mathrm{O}, 0.25 \mathrm{~g}$; ; boric acid, 0.10 g.; ammonium molybdate, 0.02 g.; $\mathrm{MnSO}_{4} .4 \mathrm{H}_{2} \mathrm{O}$, 0.04 g.; $\mathrm{ZnSO}_{4} .4 \mathrm{H}_{2} \mathrm{O}, 0.04 \mathrm{~g} . ; \mathrm{CuSO}_{4} .5 \mathrm{H}_{2} \mathrm{O}, 0.045 \mathrm{~g}$.; $\mathrm{HCl}$ (conc.), 2 drops. $1 \mathrm{ml}$. of solution $\mathrm{B}$ was added to the basal solution. The combined solutions were adjusted to $\mathrm{pH} 5.5$ with A. R. KOH solution $(40 \%, w / v)$ and sterilized in a 101 . pyrex aspirator at $15 \mathrm{lb}$. for $15 \mathrm{~min}$.

(iii) Growth factor solution

The following were dissolved in distilled water and made up to $100 \mathrm{ml}$.:

inositol, 1.0 g.; pyridoxine hydrochloride, $250 \mathrm{mg}$; calcium D-pantothenate, $240 \mathrm{mg}$.; thiamine hydrochloride, $200 \mathrm{mg}$; nicotinic acid, $200 \mathrm{mg}$; folic acid, $10 \mathrm{mg}$; D-biotin, $0.22 \mathrm{mg}$. This solution was separately sterilized in $8 \mathrm{ml}$. portions at $10 \mathrm{lb}$. instantaneously and then added aseptically to the bulk of the medium.

(iv) Phenol (A.R.)

Apparatus. Medium was fed by a metering pump to the $250 \mathrm{ml}$. culture vessel which was stirred magnetically and fitted with an overflow tube which maintained the culture volume at $150 \mathrm{ml}$. The vessel was surrounded by a glass jacket through which water at $30^{\circ}$ was pumped. Aeration was provided by a small aquarium pump sparging air at about $15 \mathrm{l}$./hr through a sintered glass diffuser. A sampling device (Heatley, 1950) was initially used to transfer an active culture of the yeast into the vessel, and the pump rate was then adjusted to correspond with a dilution rate of $0.2 \mathbf{h r}^{-1}$. Equilibrium was judged to be achieved when the yeast content and the phenol concentrations were similar on consecutive daily tests.

Yeast concentration. Yeast concentration was measured as extinction in a Unicam SP 500 spectrophotometer operating at $650 \mathrm{~m} \mu$. Results were expressed as dry weights by means of a standard curve relating extinctions to weight of organisms dried at $120^{\circ}$ for $16 \mathrm{hr}$. 
Phenol concentration. Phenol content within the culture vessel was estimated by a method based on that of Snell \& Snell (1937) using a $0.4 \%(w / v)$ solution of 2,6-dibromoquinonechloroimide in absolute ethanol. The reagent was stable for a week at about $-2^{\circ}$. For the assay, $4.5 \mathrm{ml}$. solution was diluted with $95.5 \mathrm{ml}$. distilled water and a $2 \mathrm{ml}$. portion added to $1 \mathrm{ml}$. $\mathrm{m}$-bicarbonate buffer $(\mathrm{pH} \mathrm{9 \cdot 4)}$ ) and $1 \mathrm{ml}$. of test solution in a test-tube. The tube was shaken and held at $37^{\circ}$ in a water bath for precisely $1 \mathrm{hr}$ and the extinction of the solution at $625 \mathrm{~m} \mu$ was recorded with a Unicam SP 500 spectrophotometer against a diluted reagent blank. Phenol concentration was directly proportional to the extinction, whereas similar concentrations of catechol (which was often present in the culture vessel) gave very low readings.

Manometric measurements. Oxygen uptake of yeast suspensions was determined by the direct method described by Umbreit, Burris \& Stauffer (1957).

\section{RESULTS}

Four continuous cultures $a, b, c$ and $d$ were done with media containing $3,6 \cdot 65,9$ and $12 \mu \mathrm{moles}$ phenol $/ \mathrm{ml}$. as the sole source of carbon and equilibrium conditions were established for a range of dilution rates (relative flow rates.) With the cultures at equilibrium, phenol content, yeast content and yeast output were estimated. Phenol contents of $a$ were low for dilution rates up to $0 \cdot 2 \mathrm{hr}^{-1}$, but at higher dilution rates phenol content rose abruptly (Fig. 1). Culture $b$ gave similar results except that the abrupt rise occurred after $0.3 \mathrm{hr}^{-1}$. In contrast, $c$ gave a long steady rise after $0.2 \mathrm{hr}^{-1}$, while $d$ provided low values until $0.1 \mathrm{hr}^{-1}$, followed by a steady rise.

For yeast content, $a$ and $b$ gave a long steady rise with increasing dilution rate and then an abrupt fall (Fig. 2). This contrasts with the short rise and long steady fall of $c$ and $d$. The values for yeast output are shown in Fig. 3; $a$ and $b$ achieved maximum output at comparatively high dilution rates but $c$ and $d$ at much lower dilution rates. Except for $d$, maximum yeast output and maximum yeast content occurred at about the same dilution rate.

The lowest dilution rate needed for complete washing out of yeasts in the four experiments was within the narrow range $0 \cdot 33-0.36 \mathrm{hr}^{-1}$. Phenol was supplied under these conditions for $a: b: c: d$ in the ratio $1 \cdot 00: 2 \cdot 33: 3 \cdot 24: 4 \cdot 32$. In contrast, at maximum yeast output, the corresponding ratio for phenol supply was $1 \cdot 00: 2 \cdot 66: 2 \cdot 40: 2 \cdot 00$.

In $a$ and $b$ the organisms were mainly discrete, single and small, only a small proportion being large and fragile. The organisms of $c$ were also of the two sizes but many were aggregated and this clumping was even more marked in $d$. The same aggregation occurred when organisms from $a$ were transferred to a batch of medium containing 10.6 $\mu$ moles phenol $/ \mathrm{ml}$. and had grown after a $50 \mathrm{hr}$ lag period. Transfer of yeast from $a$ to a batch of medium with $1.06 \mu \mathrm{mole} / \mathrm{ml}$. phenol, however, resulted in immediate growth and the organisms remained separate.

At dilution rates below $0.2 \mathrm{hr}^{-1}$, the $a$ and $b$ cultures had developed a slight fluorescent yellow coloration but in the $c$ and $d$ cultures this pigmentation of the medium was much more intense and persistent, being produced over a much wider range of dilution rates. The material imparting the colour had well marked 
absorption peaks at 375 and $445 \mathrm{~m} \mu$ and corresponded with authentic riboflavin in these and other spectrophotometric characteristics.

An inoculum of yeasts grown on $1 \mu$ mole phenol $/ \mathrm{ml}$. was used to initiate culture $c$ with a dilution rate of $0.029 \mathrm{hr}^{-1}$ being maintained. Slowly the yeast became adapted to the higher concentration of phenol and its ability to take up oxygen in the presence of phenol was measured manometrically (Table 2). As the culture

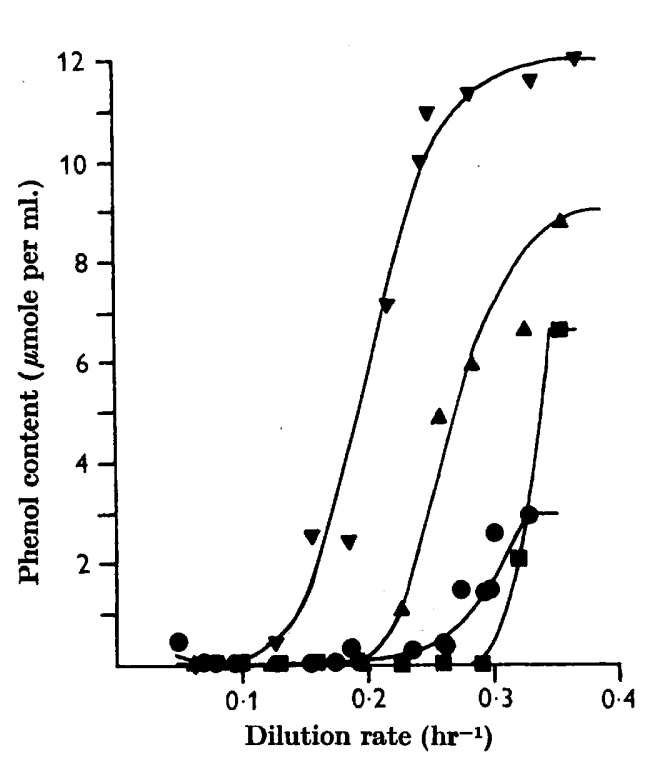

Fig. 1

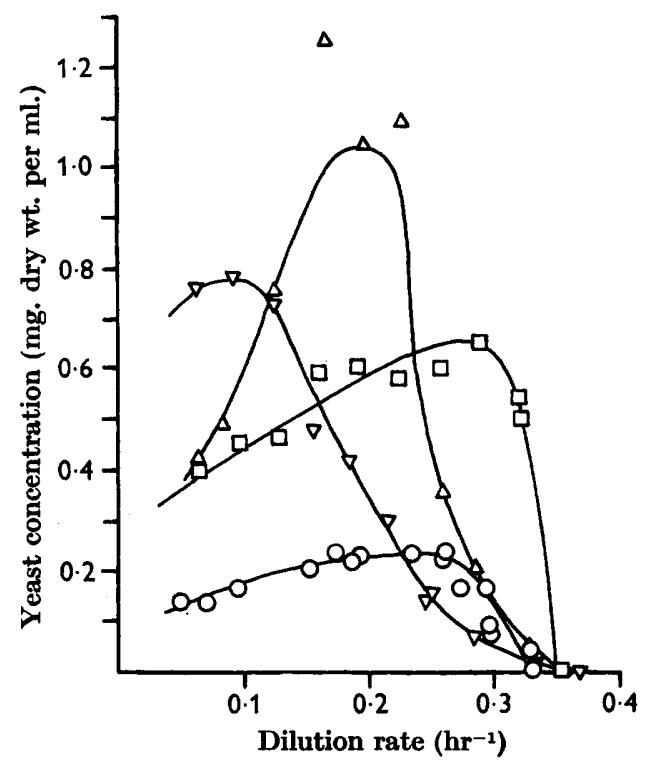

Fig. 2

Fig. 1. Phenol contents maintained in culture vessel at various dilution rates. Experiments: $a, \bigcirc-O ; b, \square-\square ; c, \Delta-\Delta ; d, \nabla-\nabla$; using media containing $3,6.65$, 9 and $12 \mu$ moles phenol/ml. respectively.

Fig. 2. Yeast contents maintained in culture vessel at various dilution rates. Symbols (as in Fig. 1): $a, O-O ; b, \square-\square ; c, \Delta-\Delta ; d, \nabla-\nabla$.

became heterogeneous, however, the manometric results showed that the ability to metabolize phenol was decreased. Furthermore, while the original adapted homogeneous population took up less oxygen in the presence of catechol than in the presence of phenol, the position was reversed for the heterogeneous population.

\section{DISCUSSION}

The results indicate that Debaryomyces subglobosus was able to metabolize substantial amounts of phenol as sole source of carbon. With 6.65 $\mu$ moles phenol $/ \mathrm{ml}$. organisms became adapted relatively easily in either batch or continuous culture but less readily at higher concentrations, and other differences observed were the disproportionately greater quantity of riboflavin produced and clumping, particularly at high dilution rates. Moreover, yeast grown in a low concentration of phenol and transferred to batch cultures with comparatively high concentrations grew only after a long period. The extended lag period and the clumping which 


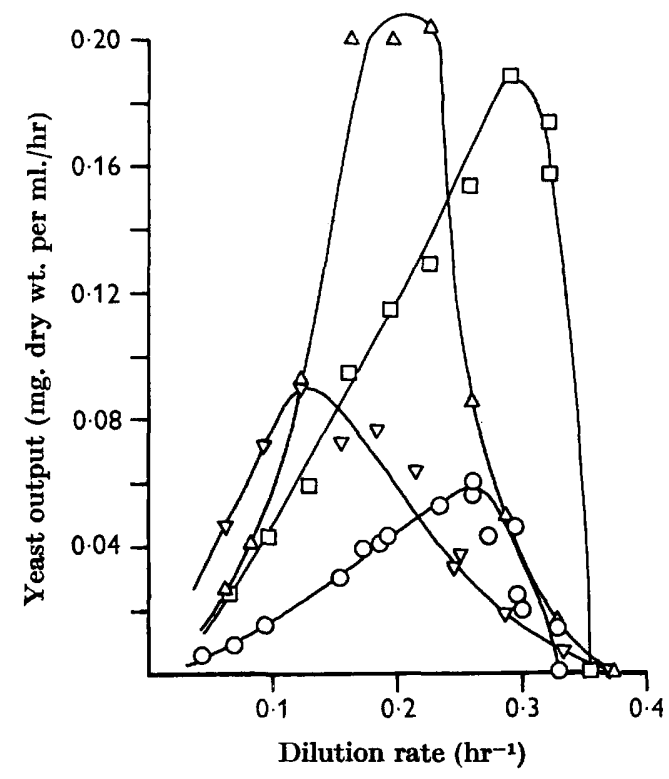

Fig. 3

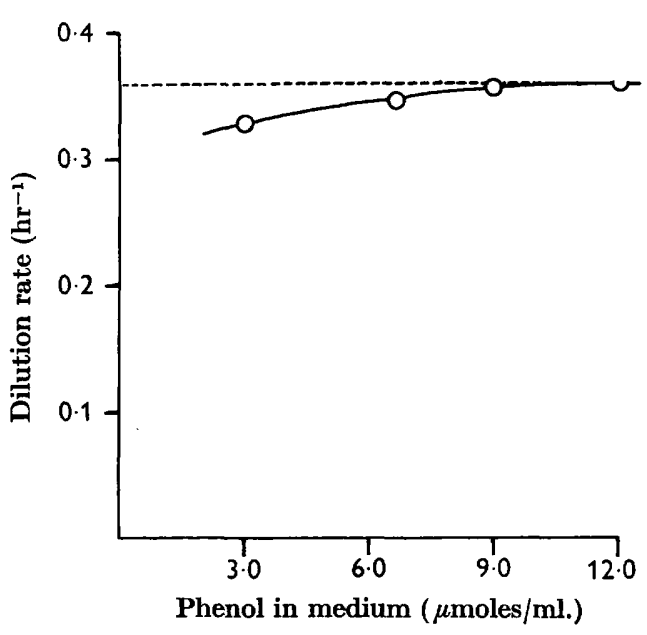

Fig. 4

Fig. 3. Yeast output from the culture vessel at various dilution rates. Symbols as in Fig. 2.

Fig. 4. Relationship between dilution rate just giving washout (critical dilution rate) and the concentration of phenol in the medium supplied.

Table 2. Oxygen uptake of yeasts growing continuously on 9 umoles phenol/ml.

Yeasts grown batchwise on $1 \mu \mathrm{mole}$ phenol $/ \mathrm{ml}$. were used in the continuous culture, with dilution rate of $0.029 \mathrm{hr}^{-1}$, sampled early and at the end of the adaptation period (10 and $80 \mathrm{hr}$ after inoculation). Samples were offered either phenol (5 $\mu$ moles), catechol ( $5 \mu$ moles) or medium without phenol in the Warburg respirometer.

\begin{tabular}{|c|c|}
\hline \multicolumn{2}{|c|}{$\begin{array}{l}\text { Oxygen uptake after } \\
80 \mathrm{~min}(\mu \mathrm{l} .)\end{array}$} \\
\hline $\begin{array}{c}\text { Early } \\
\text { sample }\end{array}$ & $\begin{array}{c}\text { Late } \\
\text { sample }\end{array}$ \\
\hline 63 & 185 \\
\hline 242 & 550 \\
\hline 507 & 243 \\
\hline
\end{tabular}

occurred in batch and continuous cultures could be interpreted as an adaptation to the presence of relatively high concentrations of a metabolic inhibitor. But associated with this adaptive change the yeast population became less able to utilize the phenol. Some of the organisms may have retained their original ability in spite of the higher phenol content, while the rest became either less efficient at metabolizing phenol or were unable to utilize it at all. Because there is strong evidence that phenol is oxidized by yeasts to catechol and because the heterogeneous population metabolized catechol more strongly than phenol, it is possible that many of 
the organisms were attacking extracellularly the catechol produced from phenol by the rest of the population.

Maximum yeast output (mg./ml./hr) for cultures $a, b, c$ and $d$ occurred at dilution rates $\left(D_{M}\right)$ of $0.26,0.30,0.21$ and $0.13 \mathrm{hr}^{-1}$, a reflexion of the somewhat toxic properties of the media in $c$ and $d$ and the relatively poor supply of substrate in $a$. The medium used for $b$ gave both the highest dilution rate and rate of input of phenol for maximum yeast output (Table 3). It was the more toxic medium $c$, however, which gave the highest values for yeast concentration in the vessel and the

Table 3. Comparison of continuous cultures using four levels of phenol concentration

\begin{tabular}{|c|c|c|c|c|c|c|c|c|}
\hline Expt. & $\begin{array}{c}\text { Phenol } \\
\text { conc. } \\
\text { in } \\
\text { medium } \\
\text { ( } \mu \text { mole/ } \\
\text { ml.) } \\
\left(S_{R}\right)\end{array}$ & $\begin{array}{c}\text { Dilution } \\
\text { rate } \\
\text { giving } \\
\text { max. } \\
\text { output } \\
\left(D_{M}\right)\end{array}$ & $\begin{array}{c}\text { Phenol } \\
\text { input } \\
\text { at } D_{M} \\
\left(S_{R} \cdot D_{M}\right)\end{array}$ & $\begin{array}{c}\text { Max. } \\
\text { yeast } \\
\text { conc. } \\
\text { achieved n } \\
(\mathrm{mg} . \\
\text { dry wt./ml. })\end{array}$ & $\begin{array}{l}\text { Dilution } \\
\text { rate } \\
\text { giving } \\
\text { max. yeast } \\
\text { conc. } \\
\left(D x_{M}\right)\end{array}$ & $\begin{array}{l}\text { Phenol } \\
\text { input } \\
\text { at max. } \\
\text { yeast } \\
\text { conc. } \\
\left(S_{R} \cdot D x_{M}\right)\end{array}$ & $\begin{array}{c}\text { Apparent } \\
\text { yield } \\
\text { at max. } \\
\text { yeast } \\
\text { conc. } \\
\text { (mg. dry } \\
\text { wt. } / \\
\mu \mathrm{mole} \text { ) }\end{array}$ & $\begin{array}{c}\text { Dilution } \\
\text { rate } \\
\text { at } \\
\text { wash- } \\
\text { out } \\
\left(D_{c}\right)\end{array}$ \\
\hline$a$ & 3.0 & 0.26 & 0.78 & 0.23 & 0.26 & 0.78 & 0.09 & $0 \cdot 33$ \\
\hline$b$ & $6 \cdot 65$ & 0.30 & 2.00 & 0.65 & 0.29 & $1 \cdot 93$ & $0 \cdot 10$ & $0 \cdot 35$ \\
\hline$c$ & $9 \cdot 0$ & 0.21 & 1.89 & 1.05 & $0 \cdot 20$ & 1.80 & $0 \cdot 12$ & 0.86 \\
\hline$d$ & $12 \cdot 0$ & $0 \cdot 13$ & 1.56 & 0.78 & 0.09 & 1.08 & 0.07 & 0.36 \\
\hline
\end{tabular}

highest output: input ratio (that is the apparent yield values). This may have been because of the greater clumping of organisms in $c$. With discrete yeasts there was both regular division and regular loss of a proportion of the organisms in the continuous culture, but with clumps such regularity was impaired. The clumps varied both in size and in the age of their organisms; they fragmented either because of mechanical damage or growing larger than a critical size. This led to a spread of mean generation times of the organisms, discrete and aggregated, and to a low average growth rate.

With low dilution rates small yeast concentrations were maintained, particularly for media containing little phenol. This may have resulted from the very high endogenous metabolism of the population which accounted for the utilization of much of the phenol supplied. The amount of substrate left for growth therefore became progressively smaller at lower dilution rates, giving a progressively smaller population.

In contrast with bacteria, yeasts grow poorly at very low dilution rates because of the high endogenous metabolism, and are also washed out of the culture vessel at lower dilution rates. The yeasts at the point of washout are under considerable selection pressure with only the fastest growing surviving but surprisingly $a, b, c$ and $d$ washed out at dilution rates ranging only from 0.33 to $0.36 \mathrm{hr}^{-1}$ (Table 3). Certain organisms adapted in $d$ must therefore have grown as quickly as those in $a$, despite the large difference in phenol content of the media.

In this connexion, Ware \& Evans (1959) were able to cultivate continuously bacteria in phenolic media at dilution rates as high as $0.55 \mathrm{hr}^{-1}$ and with a concentration of $3750 \mathrm{mg}$. phenol $/ \mathrm{l}$. (40 $\mu \mathrm{moles} / \mathrm{ml}$.) in the medium and $15 \mathrm{mg}$. $/ \mathrm{l}$. in the effluent. Moreover Evans \& Kite (1961), with Pseudomonas aeruginosa, were able to increase the dilution rates for phenol media to $c .0 \cdot 66 \mathrm{hr}^{-1}$ and to $c .0 .77 \mathrm{hr}^{-1}$ 
with mixed bacterial cultures. With a non-toxic source of carbon present, rates of about $3 \mathrm{hr}^{-1}$ were mentioned. On these grounds it would seem that yeasts are unlikely to be important commercially in the removal of phenol from effluents because of their slowness in adaptation, growth and uptake of phenol. It may be, however, that yeasts are more acceptable as a source of protein for animal feeding than pseudomonads. From the point of view of effluent utilization, the more slowly growing yeasts might therefore be worth investigation.

\section{APPENDIX: THEORETICAL CONSIDERATIONS}

Simple mathematical descriptions of continuous cultures have been produced where organisms are dispersed and fed with a medium in which one essential foodstuff is in limiting concentration (Monod, 1950; Novick \& Szilard, 1950). Experimental results agree with calculated values in some cases (Herbert, Elsworth \& Telling, 1956) but in others the yield of organisms per unit substrate varies with dilution rate (Herbert, 1958). For instance at low dilution rates, certain microorganisms produce poor yields because the supply of nutrients is barely sufficient to meet the requirements for maintenance. At higher dilution rates, these demands are fully met and any additional nutrient available is used for growth. This means that the highest concentration of organisms is achieved, not at the lowest dilution rate but at a rate between zero flow and the point of washout.

Results of the present work are of interest because of the toxicity of the medium, and therefore values based on mathematical relationships derived by Herbert $e t$ al. (1956) were calculated. For this purpose, values for maximum rate of growth $\left(\mu_{\text {max. }}\right)$, saturation constant $\left(K_{s}\right)$ and yield constant $(Y)$ are needed.

In batch culture of adapted yeasts grown on a medium containing $0.01 \%$ phenol as sole source of carbon, $\mu_{\mathrm{max}}$, was $0.1133 \mathrm{hr}^{-1}$. It might be expected that a similar value would apply to continuous culture, but the following considerations refute this. On the basis of theory (Herbert et al. 1956)

$$
\mu_{\max .}=D_{c} \frac{\left(K_{s}+s_{R}\right)}{s_{R}},
$$

where $D_{c}$ is the dilution rate at which washout occurs and $s_{R}$ is the concentration of limiting substrate in the medium supplied. In practice, $K_{s}$ is normally small compared with $s_{R}$ and therefore the expression $\left(K_{s}+s_{R}\right) / s_{R}$ is almost unity, especially when $s_{R}$ is large.

If this be so, then $\mu_{\text {max. }}$ should almost equal $D_{c}$ which ranges from $0.328 \mathrm{hr}^{-1}$ in $a$ to 0.360 in $d$. When $D_{c}$ is plotted against $s_{R}$, the relationship can be shown to be roughly asymptotic to the value $\mathbf{0 \cdot 3 6 0}$. This value for $D_{c}$, and hence $\mu_{\max ,}$, is very different from $\mu_{\max }$ calculated from batch culture work. Because $\mu_{\max }$ and $K_{s}$ are intimately related, it might be expected that similar discrepancies would occur in values calculated for $K_{s}$ from batch and continuous cultures. Again on the basis of theory, the cell concentration,

$$
x=Y\left[s_{R}-K_{s}\left(\frac{D}{\mu_{\max .}-\bar{D}}\right)\right],
$$

and therefore

$$
D_{x}=D Y\left[s_{R}-K_{s}\left(\frac{D}{\mu_{\text {max. }}-D}\right)\right] \text {. }
$$


As $D$, the dilution rate, increases from zero to $D_{c}, x$ falls to zero. There will be a value of $D$ where $x$ is greatest and it is convenient to term this $D_{\mu}$. By differentiating the above equation and equating to zero, we can arrive at an expression for $D_{M}$. Thus

$$
D_{M}=\mu_{\max .}\left\{1-\sqrt{\frac{K_{s}}{K_{s}+s_{R}}}\right\} .
$$

The values for $D_{M}$ in $a$ and $b$ were recorded as $0 \cdot 262$ and $0 \cdot 290 \mathrm{hr}^{-1}$ respectively, but in $c$ and $d$ were considerably lower $(0 \cdot 21$ and $0 \cdot 13$ respectively), presumably because of clumping and other toxicity effects. Values for $K_{s}$ calculated on the basis of the above $D_{M}$ results for $a$ and $b$, are $0 \cdot 2401$ and $0.2613 \mu \mathrm{mole} / \mathrm{ml}$. respectively. An alternative approach is to calculate values for $K_{s}$ by substituting in equation (1). This gives $K_{s}$ as 0.292 for $a$ and $0.269 \mu \mathrm{mole} / \mathrm{ml}$. for $b$. These four estimates of $K_{s}$ were averaged to give $0.266 \mu \mathrm{mole} / \mathrm{ml}$. or $24.96 \mathrm{mg} . / \mathrm{l}$.

To arrive at a satisfactory value for $Y$, each recorded yield value in $a, b, c$ and $d$ was plotted against the appropriate dilution rate. The results (Fig. 5) give high correlation coefficients of $+\mathbf{0 . 6 4 4}$ and $+\mathbf{0 . 9 8 3}$ for $a$ and $b$ respectively, but a low degree of correlation for $c$ and $d(-0 \cdot 110$ and $+0 \cdot 194$ respectively). The lines of best fit for $a$ and $b$ were calculated and extrapolated to give $Y$ values at $D_{c}$. At $D_{c}$ it might be expected that a large proportion of the phenol taken up by the organism would be directed to cell division. The $Y$ values arrived at on this basis were $0 \cdot 118$ for $a$ and 0.115 for $b$, giving a mean value of $0.1165 \mathrm{mg}$. dry wt. $/ \mu$ mole.

Having arrived at values for $\mu_{\max }, K_{\mathrm{s}}$ and $Y$, it is possible to derive values for $x$ and $s$ for a range of values of $D$ based on the following equations:

$$
\begin{gathered}
x=Y\left(s_{R}-s\right), \\
s=K_{s}\left(\frac{D}{\mu_{\max }-D}\right) .
\end{gathered}
$$

A comparison between the calculated values for $x$ and $s$ and the corresponding experimental results is shown in Fig. 6. For $x$ values there are clearly considerable discrepancies at low dilution rates, with the experimental results being considerably ower. At higher dilution rates there is reasonable conformity in $a$ and $b$, but wide deviations from the expected results in $c$ and $d$. This is probably due to the toxic effects of phenol in $c$ and $d$ which lead to clumping and heterogeneity of the yeasts.

For $s$ values, it is clear that in $a$ and $b$ rather more phenol is taken up than would be expected at high dilution rates. This may arise because the metabolic step of phenol to catechol is not rate limiting, while some of the later metabolic products might perhaps be lost, for instance 3 oxoadipate. With $c$ and $d$, less phenol is taken up than expected and this again is presumably due to the toxic effects of the medium on the yeast population.

Returning to the low $x$ values experienced at reduced dilution rates in $a, b$ and $c$, it is probable that the expected results were not realized because of the high maintenance energy requirements of the yeast strain. Some allowance has been suggested by Herbert (1958) for these requirements by modifying the basic growth equation

$$
\begin{gathered}
d x / d t=\mu x \\
d x / d t=(\mu-k) x
\end{gathered}
$$




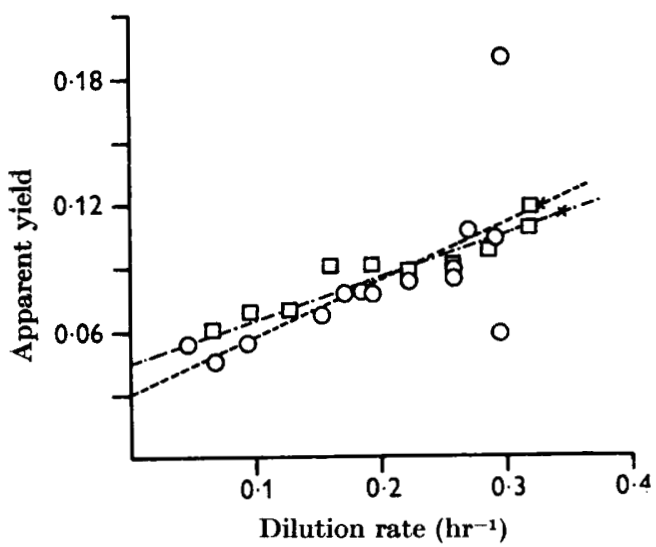

Fig. 5

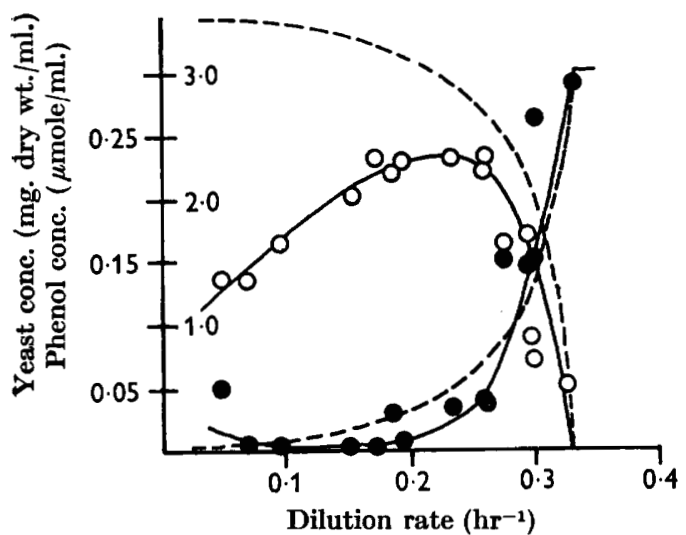

Fig. $6(a)$

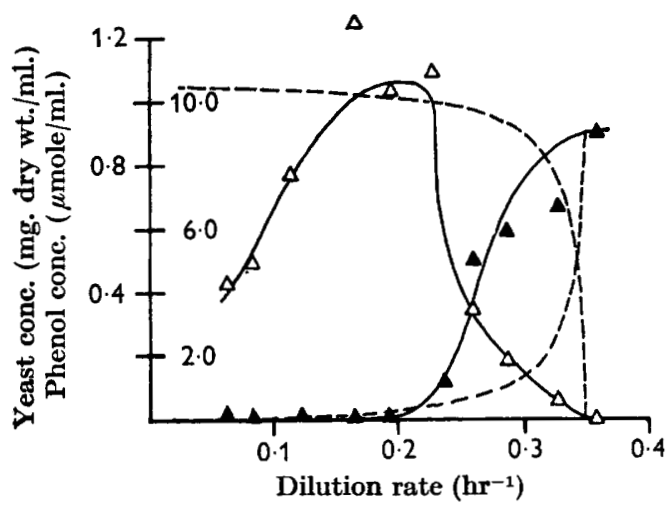

Fig. 6 (c)

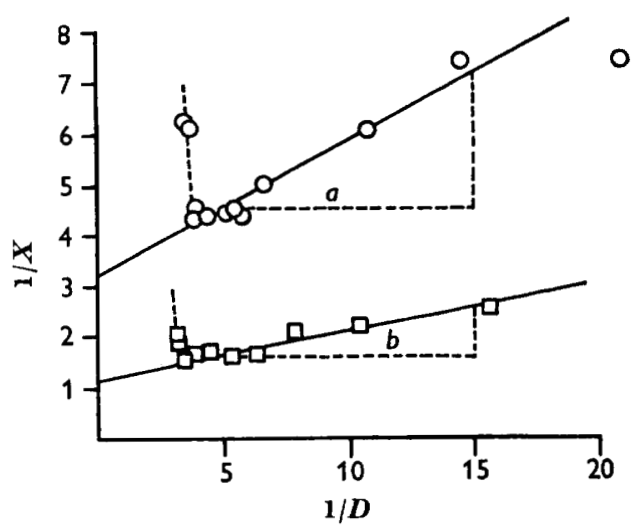

Fig. 7

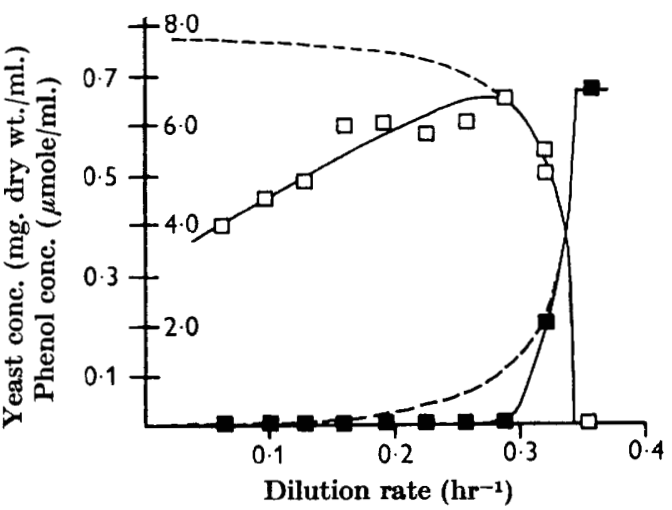

Fig. 6 (b)

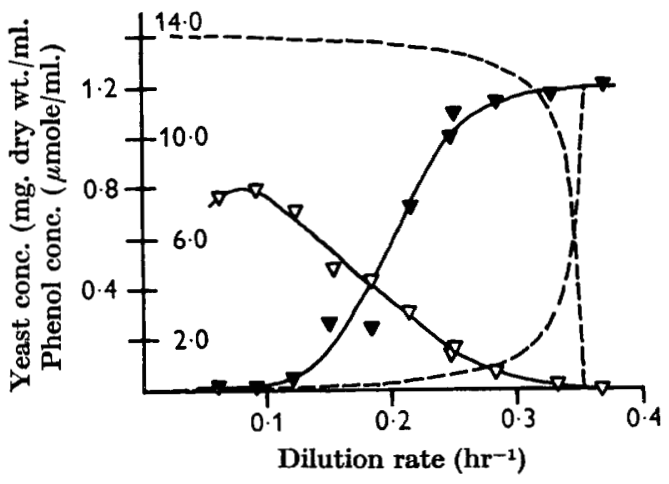

Fig. $6(d)$

Fig. 5. Relationship between apparent yield (mg. dry wt. of yeast per $\mu$ mole phenol supplied) and dilution rate. Experiments: $a, \mathrm{O}-\mathrm{O} ; b, \square-\square$; using media containing 3, and $6 \cdot 65, \mu$ moles/phenol $\mathrm{ml}$. respectively.

Fig. 6. Experiment $a$ : comparison between observed (solid lines) and expected (broken lines) results for yeast and phenol concentrations at different dilution rates. $-\rightarrow$, phenol content; - -0 , yeast content. Experiment $b$ : $-\square-\square$, phenol content; $-\square-\square-$, yeast content. Experiment $c: \Delta-\Delta$, phenol content; $-\triangle-\triangle$, yeast content. Experiment $d: \nabla-\nabla$, phenol content; $-\nabla-\nabla-$, yeast content.

Fig. 7. Plot of inverse of yeast concentration against inverse of dilution rate in order to derive a value for $k$. Experiment $a, \bigcirc-\bigcirc$; experiment $b, \square-\square ; k=(\tan A)(\max$. yeast concentration). 
where $k$ is a constant cell maintenance requirement and hence

Therefore

$$
\begin{gathered}
\mu=D+k . \\
D\left(s_{R}-s\right)=x\left(\frac{D+k}{Y}\right) .
\end{gathered}
$$

If there are no maintenance requirements, then the cell concentration in the vessel would be $x_{\max }$. which is equal to the expression $Y\left(s_{R}-s\right)$.

$$
\begin{array}{rlrl} 
& \text { Therefore } & D\left(s_{R}-s\right) & =x(D+k)\left(\frac{s_{R}-s}{x_{\max .}}\right), \\
& \text { and thus } & =x\left(\frac{D+k}{x_{\max .}}\right), \\
& \text { and hence } & x & =x_{\max }\left(\frac{D}{D+k}\right), \\
& \text { or } \quad \frac{1}{x} & =\frac{k}{x_{\max .}}+\frac{1}{x_{\max } .}
\end{array}
$$

If $1 / x$ is plotted against $1 / \mathrm{D}$ (Fig. 7) a linear relationship would be expected. Where the ordinate is intercepted, the value $1 / x_{\max }$ is given. (The slope of the line represents the value $\left.k / x_{\text {max. }}\right)$. An estimate of $k$ can therefore be derived from these two values. In the case of $a$ it is $0.0818 \mathrm{hr}^{-1}$ and for $b, 0.0842$. These values are considerably greater than that calculated by Marr, Nilson \& Clark (1963) for a strain of Escherichia coli, namely c. $\mathbf{0 . 0 2}$ and may reflect generally greater maintenance energy requirements for yeasts compared with bacteria.

The authors are grateful to Professor S. V. Perry for his help and encouragement and to the Institute of Brewing for a generous grant towards equipment. One of the authors (D.A.J. Wase) held a Ministry of Agriculture, Fisheries and Food Research Studentship during the work.

\section{REFERENCES}

Evans, C. G. T. \& KITE, S. (1961). Application of homogeneous continuous culture to the treatment of spent liquor. S.C.I. Monograph No. 12, 'Continuous Culture of Microorganisms'.

Evans, W. C. (1963). Microbiological degradation of aromatic compounds. J. gen. Microbiol. 32, $17 \%$.

Harris, G. \& RICKETTS, R. W. (1962). Metabolism of phenolic compounds by yeast. Nature, Lond., 195, 473.

Heatiey, N. G. (1950). A versatile fermentation sampling arrangement. J.gen. Microbiol. 4, 410.

Herbert, D. (1958). Some principles of continuous culture. In Recent Progress in Microbiology. Symp. 7th, int. Congr. Microbiol., Stockholm.

Herbert, D., Elsworth, R. \& Teling, R. C. (1956). The continuous culture of bacteria; a theoretical and experimental study. J. gen. Microbiol. 14, 601.

MARR, A. G., Nilson, E. H. \& Clark, D. J. (1963). The maintenance requirement of Escherichia coli. Ann. N.Y. Acad. Sci. 102, 536.

Monod, J. (1950). La technique de culture continue. Théorie et applications. Ann. Inst. Pasteur, 79, 390.

Novick, A. \& Szilard, L. (1950). Experiments with the Chemostat on the spontaneous mutation of bacteria. Proc. natn. Acad. Sci., U.S.A. 36, 708. 
Reiche, A., Hilgetag, G., Lonenz, M. \& Martini, A. (1962). Continuous production of yeast from phenol-containing substrates. In Continuous Cultivation of Micro-organisms, Proc. 2nd Symp., Prague. Czechoslovak Academy of Science.

Snell, F. D. \& S Sell, C. T. (1937). Colorimetric Methods of Analysis. New York: Van Nostrand.

Umbreit, W. W., Burris, R. H. \& Stauffer, J. F. (1957). Manometric Techniques. Minneapolis: Burgess.

WARE, G. C. \& Evans, C. G. T. (1959). Some preliminary experiments on the treatment of phenolic trade effluents by continuous culture. Folia Microbiologica, 4, 62 . 